International Journal of Engineering \& Technology, $7(4.5)(2018) 428-457$
International Journal of Engineering \& Technology
SPC
Website: www.sciencepubco.com/index.php/IJET
Research paper

\title{
Production of Brown's Gas using Hydroxy Generator
}

\author{
Dr. Venkata Ramesh Mamilla ${ }^{{ }^{*}}$, K. Sri Rama Murthy ${ }^{2}$, M.Vamsi Krishna ${ }^{3}$, T.S.S.S ManikanthaSwamy ${ }^{4}$, \\ A.Ramesh ${ }^{5}$,M.Uday Krishna ${ }^{6}$ \\ ${ }^{I}$ Professor and HOD, Sri Vasavi Engineering college, Tadepalligudem, W.G.District,AP,India. \\ ${ }^{2}$ Senior Assistant Professor, Sri Vasavi Engineering college, Tadepalligudem, W.G.District,AP,India. \\ ${ }^{3,4,5,6}$ UG Students, Sri Vasavi Engineering College, Tadepalligudem, W.G.District,AP,India. \\ *Corresponding author E-mail: maa_ram@yahoo.co.in
}

\begin{abstract}
This paper deals with the designing of hydroxyl (HHO) generator and thus use the Brown's Gas liberated from it as a supplement to increase fuel efficiency in IC engines. The combustion process in IC engines is very primitive and hence unburnt fuel remains after the combustion process. This is a very challenging problem being faced by today's automobile industry as this unburnt mixture is a serious air pollutant. The proposed approach is based on an ordinary HHO generator. Although people use HHO generators in practice a very little research has been carried out in implementing an efficient system. This project is mainly focused on finding an efficient configuration of an ordinary HHO generator that is efficient than an ordinary system. Here the generator was tested under several conditions in order to determine a convenient design for an efficient $\mathrm{HHO}$ generator.
\end{abstract}

Keywords: Production; Brown's Gas; Hydroxy Generator;

\section{Introduction}

Due to increase in population, the use of automobiles increased drastically which resulted in increase of usage of fossil fuels. Also the Industrial sector is growing day by day. This resulted in depletion of these resources and increase in pollution. The solution to the above problem is to use an alternate fuel. There are many alternate fuels and some of them are even applied and being used. But they require new designs to use them and heavy modifications or complete replacement of current running equipment. The number of these equipment or automobiles to which the alternate fuels cannot be implemented are in millions. So we need an alternate source which doesn't require heavy modifications to current vehicles.

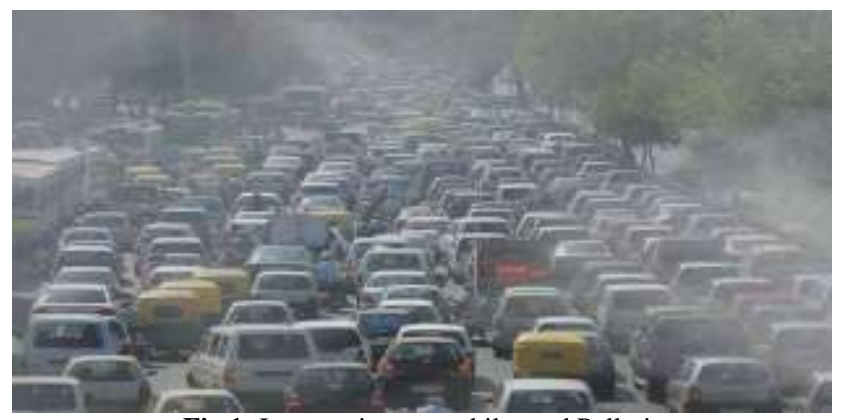

Fig 1: Increase in automobiles and Pollution

\subsection{Efficient Alternate Fuel}

The most efficient alternate fuel of the above listing is 'Hydrogen'. It has almost the same calorific value as the petrol. Hydrogen is widely abundant around us in the form of water. If we can find an efficient and apt process to extract it from water we get ourselves a clean energy source as the byproduct of Hydrogen burnt is water again.

\subsubsection{About Hydrogen}

Atomic Number $\quad: 1$

Appearance : Colorless

Phase (at STP) : Gas

Density (at STP) $\quad: 0.08988 \mathrm{~g} / \mathrm{L}$

Thermal Conductivity: $0.1805 \mathrm{~W} / \mathrm{mK}$

Molar Heat Capacity : $28.836 \mathrm{~J} /(\mathrm{mol}-\mathrm{K})$

Heat of Vaporization : $0.904 \mathrm{KJ} / \mathrm{mol}$

Net Calorific Value : $121000 \mathrm{KJ} / \mathrm{Kg}$

There are many sources from which Hydrogen can be extracted. It can be extracted from Acetylene or from Water.

\subsubsection{Extraction of Hydrogen}

Hydrogen itself is not of any use. A combination of Hydrogen and Oxygen is required for it to work as fuel.

Extraction of Hydrogen from Acetylene requires chemical processes and is more costly. Only Hydrogen is produced in this process.

Whereas extraction of Hydrogen from water is the best way because it produces a mixture of hydrogen and oxygen also called as 'oxyhydrogen' or 'Brown's Gas'. This is a highly combustible mixture which has more calorific value than base hydrogen molecule. 


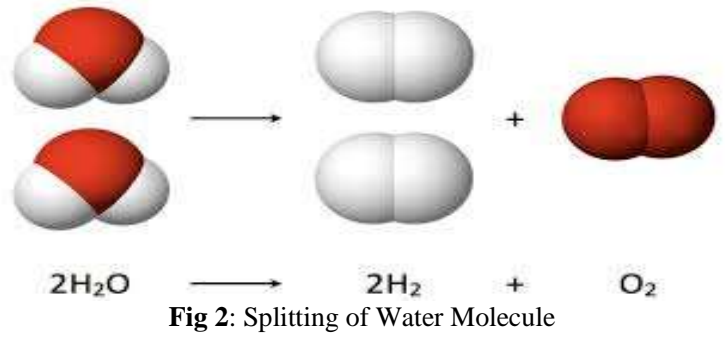

\section{Fabrication of HHO Dry Cell}

The major components required for the Fabrication of HHO dry cell are

- Electrodes

- Electrolyte

- Non Conducting Side plates for containment

- Sealing Material

- Reservoir for Electrolyte

- Bubbler Tank

- Fittings and Hoses for connecting

- Bolts and Nuts for Fastening the arrangement

\subsection{Electrodes}

Any conducting material in general can be used as an electrode. But for the cell to be efficient and to be healthy only certain electrodes are selected for this Project.

The following are the Electrode Materials that can be used.

- Iron Plates

- Stainless Steel Plates

- Graphite Plates

- Copper Plates

- Aluminum Plates

\subsubsection{Iron Plates}

Iron is the most abundant and cheapest conducting metal available in the market in different shapes and sizes. But using of Iron plates decreases the life of the cell as iron oxidizes inside water and the rust will be precipitated in the cell and contaminates the electrolyte.

$\mathrm{Fe} 3+(\mathrm{aq})+3 \mathrm{OH}-(\mathrm{aq}) \rightarrow \mathrm{Fe}(\mathrm{OH}) 3(\mathrm{~s})$

So use of Iron as Electrode can be ruled out for the fabrication of a hydroxyl generator.

\subsubsection{Stainless Steel Plates}

Stainless Steel plates are a little costly but are very high resistant to corrosion. They even conduct electricity well. This makes it ideal for it to be used as an electrode material. They have more life than the iron plates and do not form precipitates.

Stainless Steel does not react while electrolysis so no major chemical reactions occurs.

\subsubsection{Graphite Plates}

Graphite is the most conductive material in the list. It is also so inert that it wont react as much as steel does. If one can procure these graphite plates it is the best electrode than stainless steel. There will be no reaction if we use graphite as an electrolyte.

\subsubsection{Copper Plates}

Copper is a highly conductive metal but very corrosive of all. If we use copper we require $\mathrm{H} 2 \mathrm{SO} 4$ as electrolyte and it in turn forms copper sulphate precipitate and blocks the pipes.
$\mathrm{H} 2 \mathrm{SO} 4==2 \mathrm{H}(+)+\mathrm{SO} 4(2-)$

$\mathrm{Cu}(2+)+\mathrm{SO} 4(2-)==>\mathrm{CuSO} 4$

\subsection{Electrolyte}

A solution which provokes conduction is called as an electrolytic solution. There should be a solvent and a solute to form a solution. Solvent: Solvent used here is unanimously water because we need to produce hydrogen from water. We need to use deionized water or distilled water because the impurities in normal water make the efficiency lower.

Solute:Solute should be any salt or something that imparts free electrons into water. Care should be taken while selecting solute chemical because it drastically changes the efficiency and safety of the Hydroxy Generator.

The following are the list of chemicals that can be used as solute.

- Vinegar (Acetic Acid) $-\mathrm{H}_{3} \mathrm{C}-\mathrm{COOH}$

- $\quad$ Baking Soda (Natiumbicarbonate)- $\mathrm{NaHCO}_{3}$

- $\quad$ Sodium Hydroxide (Lye)- $\mathrm{NaOH}$

- $\quad$ Potassium Hydroxide- $\mathrm{KOH}$

\subsubsection{Vinegar as Solute}

Vinegar is available everywhere at low cost. The electrodes stay clean when vinegar is used. But the whole apparatus spells if we use vinegar and also it may effect the plastic parts used because of its acidic property.

So it is not best suited for this purpose.

\subsubsection{Baking Soda}

Baking soda is cheap and also available everywhere. It has a pleasant odor. But the Baking Soda leaves a brown residue after a few days of operation. It also produces $\mathrm{CO}_{2}(30 \%)$ and $\mathrm{CO}(4 \%)$ while electrolysis. The $\mathrm{CO}_{2}$ liberation and $\mathrm{CO}$ liberation is not good and poisonous.

Electrolysis

$2 \mathrm{Na}++2 \mathrm{e}-+2 \mathrm{H} 2 \mathrm{O} \rightarrow 2 \mathrm{NaOH}+\mathrm{H} 2$ and $\mathrm{HCO} 3-+\mathrm{H} 2 \mathrm{O} \rightarrow$

$\mathrm{H} 2 \mathrm{CO} 3+\mathrm{OH}-$

$\mathrm{H} 2 \mathrm{CO} 3 \rightarrow \mathrm{H} 2 \mathrm{O}+\mathrm{CO} 2$

$\mathrm{CO} 2+2 \mathrm{H}++2 \mathrm{e}-\longrightarrow \mathrm{CO}+\mathrm{H} 2 \mathrm{O}$

$\mathrm{CO}+2 \mathrm{H}++2 \mathrm{e}-\rightarrow \mathrm{C}+\mathrm{H} 2 \mathrm{O}$

\subsubsection{Sodium Hydroxide ( $\mathrm{NaOH})$}

Sodium Hydroxide is available in pellets and is in very purified form. It is not that costly. Using it with distilled water gives maximum efficiency and is clean. There will be no byproduct when this is used as solute.

\subsubsection{Potassium Hydroxide (KOH)}

Potassium Hydroxide is also inert during electrolysis and only acts as ionizer. It is also available in pure form. This keeps the water and the electrodes clean.

\subsection{Best Electrolyte or Solute}

The best electrolyte is selected by its ability to remain inert during the electrolysis process. From the above list the best electrolyte is Sodium Hydroxide and Potassium Hydroxide because of their inertness.

\subsubsection{Selected Electrolyte}

The electrolyte that has been selected for this project is Sodium Hydroxide $(\mathrm{NaOH})$. It is selected because of its inertness and availability. It is also available cheaply. Whereas Potassium Hydroxide on the other hand is costly and less available. 


\subsection{Sealing Material}

The sealing material should be like a gasket such that it preserves the electrolyte froms leaking and supports the reaction. A rubber O-Ring of diameter 5 inches and thickness $4.5 \mathrm{~mm}$ would suffice.

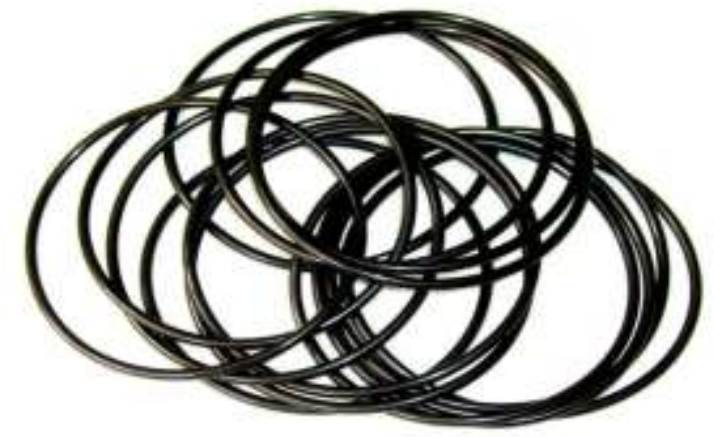

Fig 3: O-Rings

\section{Reservoir for Electrolyte}

It is already discussed that in dry cell type the electrolyte circulates between electrodes and O-Rings. So a Reservoir tank is needed for the supply and collection of electrolyte. The Reservoir tank should be non-conducting and hence plastic is the best option for this tank.

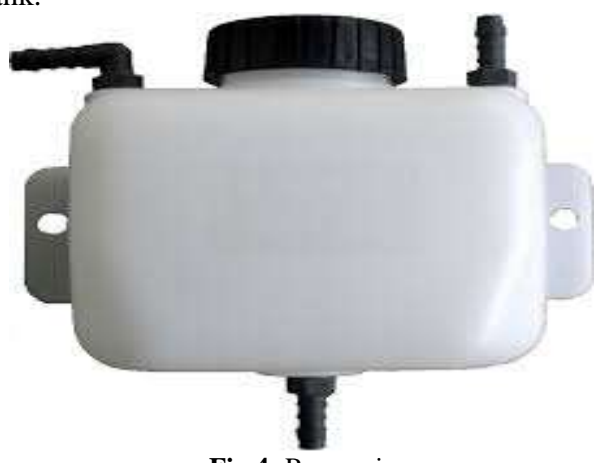

Fig 4: Reservoir

\section{Fabricated Model of Hydroxy Generator}

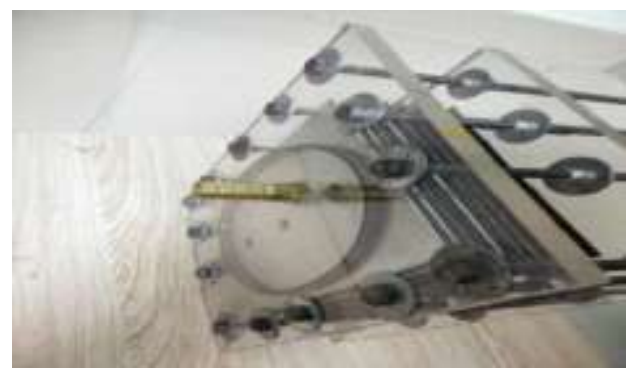

Fig 5:Fabricated Fig

\section{Results and Discussions}

Along with the above stated parameters HHO production depends on the power given to the generator. It is observed from the Literature Surveys and previous experiences that the cell takes and produces $\mathrm{HHO}$ on whatever power we give to it. But the more power given it generates more heat. So it is mandatory to find out the optimal power that should be given. For different sizes of electrodes different amount of power is required.

\section{Conclusion}

From careful observation and experimentation it is concluded that the optimal size of electrodes should be $5 * 5$ inches and for optimal power distribution a voltage regulator such as a Pulse Width Modulator is necessary to regulate the voltage based on temperature.

HHO generator is a very efficient approach to increase the fuel efficiency by increasing the energy produced per mole of fuel during the combustion process. As a result the amount of unburnt fuel in the combustion chamber was decreased.

\section{References}

[1] HarshalVashi, G.T. Haldankar, Dr. Y. S. Rao "Reduction of fuel Consumption in Engines using HHO gas"'IJARSEvol:5,special issue (1), February 2016 pp 59-67.

[2] Pranay N. Patel ,Mr. Hitesh, K. Solanki, Mrs. Vandana ,Y. Gajjar "Experimental Investigation of Hydrogen Port Fuel As a Part of Suppliment on 4-Stroke SI Engine" IJSRD vol:2,issue 03,2014.ISSN(ONLINE):2321-0613

[3] TS De Silva, L Senevirathne and TD Warnasooriya "HHO Generator- An Approach to Increase Fuel Efficiency in Spark Ignition Engines" EJAET, 2015,2(4):1-7. ISSN:2394-658X

[4] Tarkeshwar C. Patil, Siddhartha P. Duttagupta,Shrikant G. Kulkarni and Girish J. Phatak,"Oxygen Ion Transport through the Electrolyte in Solid Oxide Fuel Cell',ICRERA,2013.

[5] Tarkeshwar C. Patil, and Siddhartha P. Duttagupta,"Hybrid Self Sustainable Green Power Generation System for Powering Green Data Center",International Conference on Control, Instrumentation, Energy Communication,pp.331-334,2014.

[6] Verhelst S, Wallner T., "Hydrogen-fueled internal combustion engines. Prog Energy Combust Sci”, 2009;35:490e527, vol. 43, no. 6, pp. 609-615, December 1996.

[7] S. Haykin, Adaptive Filter Theory, 4th ed., Pearson Education Inc., Delhi, India,2002. 